Environnement Urbain

Urban Environment

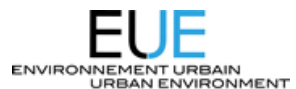

\title{
A tool for evaluating urban sustainability via integrated transportation and land use simulation models
}

\section{Hannah Maoh et Pavlos Kanaroglou}

Volume 3, 2009

Urbanisme et développement durable

Urban Planning and Sustainable Development

URI : https://id.erudit.org/iderudit/037599ar

DOI : https://doi.org/10.7202/037599ar

Aller au sommaire du numéro

\section{Éditeur(s)}

Réseau Villes Régions Monde

ISSN

1916-4645 (numérique)

Découvrir la revue

Citer cet article

Maoh, H. \& Kanaroglou, P. (2009). A tool for evaluating urban sustainability via integrated transportation and land use simulation models. Environnement

Urbain / Urban Environment, 3, 28-46. https://doi.org/10.7202/037599ar
Résumé de l'article

Cet article met l'accent sur le développement d'un outil de simulation conçu pour évaluer la durabilité urbaine et élargir le champ des connaissances nécessaires à la planification future du développement urbain. Cet outil consiste en un module instrumental qui s'ajoute à l'ITLUM (concept opérationnel intégré du développement spatial et de transport), et dont l'étalonnage a été adapté à deux villes canadiennes : Hamilton, Ontario et Halifax, Nouvelle-Écosse. Dans ces modèles, le progrès vers la durabilité est jaugé aux moyens d'indicateurs gradués pour baisser les impacts environnementaux et sociaux tout en haussant les bénéfices économiques. Dans ce but, les méthodes employées dans la conception de ces indicateurs de durabilité sont identifiées et expliquées. Un exemple de simulation est inclus afin de démontrer l'efficacité de cet outil. 


\title{
A TOOL FOR EVALUATING URBAN SUSTAINABILITY VIA INTEGRATED TRANSPORTATION AND LAND USE SIMULATION MODELS
}

\author{
Hannah MAOH \\ Pavlos Kanaroglou
}

\begin{abstract}
I RÉSUMÉ
Cet article met l'accent sur le développement d'un outil de simulation conçu pour évaluer la durabilité urbaine et élargir le champ des connaissances nécessaires à la planification future du développement urbain. Cet outil consiste en un module instrumental qui s'ajoute à l'ITLUM (concept opérationnel intégré du développement spatial et de transport), et dont l'étalonnage a été adapté à deux villes canadiennes: Hamilton, Ontario et Halifax, Nouvelle-Écosse. Dans ces modèles, le progrès vers la durabilité est jaugé aux moyens d'indicateurs gradués pour baisser les impacts environnementaux et sociaux tout en haussant les bénéfices économiques. Dans ce but, les méthodes employées dans la conception de ces indicateurs de durabilité sont identifiées et expliquées. Un exemple de simulation est inclus afin de démontrer l'efficacité de cet outil.
\end{abstract}

MOTS-CLES - Durabilité, indicateurs, simulation, aménagement de l'espace, transport

\begin{abstract}
I ABSTRACT
This paper is focused on developing a simulation tool that will be used to assess urban sustainability and inform the future of urban planning. The tool is developed as an add-on module in an operational integrated transportation and land use model (ITLUM) calibrated for two Canadian cities: Hamilton, Ontario and Halifax, Nova Scotia. Progress towards sustainability is gauged based on indicators that will minimize negative environmental and social impacts while maximizing economic benefits. To this end, the methods to model the sustainability indicators are highlighted and described. A simulation example is provided to demonstrate the operability of the devised tool.
\end{abstract}

KEYWORDS - Sustainability, indicators, simulation, land-use, transportation

1 Coordonnées des auteurs : Hannah Maoh, Center for Spatial Analysis (CSpA), School of Geography and Earth Sciences, McMaster University, 1280 Main Street West, Hamilton, Ontario, Canada, L8S 4KI, courriel : maohhf@mcmaster.ca, Pavlos Kanaroglou, Center for Spatial Analysis (CSpA), School of Geography and Earth Sciences, McMaster University, 1280 Main Street West, Hamilton, Ontario, Canada, L8S 4KI, courriel :

pavlos@mcmaster.ca 


\section{INTRODUCTION}

Concerns over sustainable city planning in the last couple of decades have generated a strong sentiment against urban sprawl and its negative ramifications in North America (Brueckner, 2000). Sprawl is defined as dispersed and discontinuous suburban land development associated with low population densities and high autodependence (Handy, 2005; Carruthers and Ulfarsson, 2002). Critics argue that such development threatens the sustainability of cities due to its negative environmental, social and economic impacts. This is because it saps local resources, destroys open space and farmland, and increases the energy consumption of mobility by promoting long commutes (Newman and Kenworthy, 1999). The latter also contributes to high levels of traffic congestion and harmful emissions (Dieleman et al., 2002). Critics further argue that sprawl is responsible for the decay of downtown areas due to people and firm decentralization, leading to reduced social interaction and weakening the bonds that create a healthy society (Brueckner, 2000).

While the number of studies that sought to address the issue of urban sustainability and combat sprawl has been on the rise over the past couple of decades, little has been done on developing analytical tools that could be used to assess the future of urban sustainability for North American and for Canadian cities in particular. Questions about how particular land use development patterns or the expansion of the current urban transportation infrastructure are likely to impact urban sustainability remain unanswered. Accordingly, there is a great need for developing simulation tools and systems of urban sustainability indicators for assessing future development policies. Integrated Transportation and Land Use Models (ITLUMs) are particularly well suited to assessing such policies (Kanaroglou and Scott, 2002; Miller et al., 2004; Lautso et al., 2002; Spiekermann and Wegener, 2004; Behan et al. 2008). ITLUMs are sophisticated Decision Support Systems (DSS) that account for the interaction between the changes in urban form and travel behaviour decisions. As such, ITLUMs allow decision makers to assess the impact of land-use and transportation infrastructure projects on the evolution of urban areas. Research efforts over the past decade and a half have been focused on improving the theoretical foundations of these models (Miller et al. 2004). However, with the exception of the work done in Europe, namely the SPARTACUS "System for Planning and Research in Towns and Cities for Urban Sustainability" (European Commission, 1998), PROPOLIS "Planning and Research of Policies for Land Use and Transport for Increasing Urban Sustainability" (Lautso et al. 2002; Spiekermann and Wegener, 2004) and
PROSPECTS "Procedures for Recommending Optimal Sustainable Planning of European City Transport Systems" (May et al. 2003; Minken et al. 2003) projects, the potential of using ITLUMs to calculate indicators for evaluating urban sustainability in North America has not been fully explored.

This paper reports on efforts undertaken to extend the capabilities of IMULATE, an ITLUM developed to study transportation and land use problems in Canadian cities. Our efforts are focused on identifying a list of indicators that can be generated with IMULATE to represent the environmental, social and economic pillars of sustainability. To this end, we developed SUSTAIN, a simulation tool that can be used as an add-on module in an ITLUM to assess the sustainability of urban futures via simulations. The methods employed to model the indicators pertaining to the three pillars of sustainability are presented, and the approach by which we gauge progress towards sustainability is described. The novelty in this paper is twofold. Firstly, we propose a systematic approach to normalize the raw value vx (see section 2.3) of any indicator $x$ to be generated by IMULATE. The approach utilizes simulated land use information to optimize traffic flows via the well-known transportation problem. The idea is to calculate the theoretical minimum (vxmin) and maximum and (vxmax) values (i.e. theoretical range) for a given indicator that correspond to the least (minimum) and most (maximum) commuting patterns (i.e. commuting range). The raw value $v x$ is then normalized to a new value $v x^{*}$ on a scale of 0 to $I$ using the determined commuting range. Previous efforts relied on setting vxmin and vxmax arbitrarily, as in SPARTACUS and PROPOLIS models, which may result in errors suggesting that this indicator is influential or not. Secondly, a simple approach is proposed for determining pollution concentration due to generated traffic without the need to run dispersion models while simulating scenarios. This approach makes the devised system appealing from a practical point of view, as it avoids the intensive computer processing required to run dispersion models with current computing technology. Those efforts are new and have not been implemented in previous research. 
The remainder of this paper is organized as follows. Section two provides a background on the issue of sustainability from a land use and transportation perspective. First, a discussion of the criteria, rationale and methods proposed in the literature to assess sustainability and calculate sustainable indicators is presented. This is followed by an overview of the common methods used in the past to model sustainability with large-scale ITLUMs. Section three reports on the simulation tool developed to extend the capabilities of IMULATE. The section starts by highlighting the general structure of the IMULATE system, followed by a description of the method we used to devise the sustainability indicators module (SUSTAIN). Section four emphasizes the operability of the devised system with a simulation example. Finally, the last section provides conclusions and directions for future research.

\section{BACKGROUND}

\section{I.I Assessing urban sustainability}

The interest in assessing urban sustainability has increased since the early 1990s. Drawing on the notion highlighted by Black (2002), the sustainability of an urban system can be broadly defined as urban development and practices that should satisfy current needs without compromising the ability of future generations to meet their needs. However, it is widely argued that current urban land use and transport systems are far from sustainable. This is due to the fact that existing transportation systems contribute to global environmental problems, consume massive amounts of non-renewable resources, result in excessive numbers of fatalities and injuries, deteriorate local air quality and increase congestion. Current land uses are also unsustainable because they contribute to urban sprawl and the imbalances between jobs and housing, as well as long commutes that are considered wasteful (Ma and Banister, 2006). In light of these problems, emphasis has been placed on addressing the issue of urban sustainability in recent years.

A growing body of literature has been advocating the development of sustainable indicators to support the urban planning process (Litman, 2008; Jeon et al. 2008). Indicators in this context are standardized measures suitable for analyzing and evaluating the importance of targeted outcomes. For example, a measure such as vehicle kilometres traveled (VKT) per capita can be used as an indicator to evaluate the level of mobility in the city. Various methods have been proposed over the past decade and a half to devise sustainable indicators that could be used to gauge progress towards sustainability. The general consensus is that urban sustainability can only be achieved by addressing various aspects that are related to the three pillars of sustainability: (I) Environment, (2) Society, and (3) Economy. The existing body of literature suggests that the sustainability of alternative future policies can be evaluated by calculating several indicators (i.e. quantifiable measures of particular outcomes) pertaining to a list of pre-defined themes that correspond to the three pillars of sustainability. The objective is then to combine those indicators to identify which of the alternative policies will result with the set of indicators that minimize negative environmental and social outcomes, while maximizing economic benefits.

According to the literature, quantitative methods for assessing the trinity of environmental, social and economic parameters are broken down to either simple or complex/advanced methods (Deakin et al., 2005). Simple methods include compatibility matrices, eco-profiling, ecological footprints, environmental auditing, flag method and spider analysis. On the other hand, complex and advanced methods, as noted by Black et al. (2002), include descriptive statistics, spatial mapping, regression analysis, travel preference functions and spatial statistics. Furthermore, Deakin et al. (2005) note that contingent valuation, cost benefit analysis, hedonic analysis, multi-criteria analysis and travel cost theory are among those advanced methods used for addressing the environmental aspect of urban sustainability. Finally, predictive and large-scale simulation models are among the more advanced methods for assessing the future of urban sustainability. Examples of the latter include the SPARTACUS, PROPOLIS and PROSPECTS models. Here, a computer program is designed to capture and simulate the processes of land use changes and travel demand behaviour in an urban area (European Commission, 1998; Lautso et al., 2002; May et al., 2003; Minken et al., 2003; Spiekermann and Wegener, 2004). The system is equipped with tools that enable the analyst to translate traffic flow and land use patterns into indicators suitable for assessing the sustainability of any future land use and transportation simulated scenario.

Our review of the literature reveals the existence of a relatively large number of diverse indicators for assessing the various aspects of sustainability of an urban system. In addition, the requirements for devising indicators do not seem to explicitly state the need for considering eventual dependability between particular indicators, external influencing factors, and the relevance and relative importance of different 
actors (Basler, 1998; Morse et al., 200I). There appears to be a lack of consensus regarding indicators for assessing sustainability. Obviously, the selection of indicators requires prior knowledge of the many facets that shape the future of the city and its evolution. Kelly (1998) has identified several criteria for evaluating sustainability indicators in the study of an urban system. He notes that any devised indicator should be:

- Calculated by using already available or easily obtainable information.

- Easily understandable without ambiguity and exceptional overlapping.

- A measure of something important in its own right.

- Available with a relatively short lead-time.

- Comparable in terms of different geographical scales and the actors involved.

- User driven, i.e. useful to their intended audience.

- Policy relevant, i.e. pertinent to policy concerns.

- Highly aggregated, i.e. the final indices should be few in number.

Furthermore, Hardi and Pinter (1995) identify some additional features enabling easier implementation of particular indicators of sustainability:

- Designed in close cooperation and agreed with the actors involved from the public to the specific shareholders.

- Cover a range of effects and impacts of interest.

- Institutionalized in terms of effective laws and regulations, responsibilities for collection and maintaining databases, monitoring and regular reporting.

- Integrated into policy-making and decision processes.

Jeon and Amekudzi (2005) examine indicators of sustainable transportation in current practice. Sixteen sustainability initiatives around the world were reviewed. The findings show that while there is no standard definition for transportation sustainability, there seems to be emerging consensus that in order to be effective, it must include impacts on the economy, environment, and social well-being; it must address the causes of sustainable or non-sustainable trends; it must consider the relative levels of influence that oversight agencies have with respect to implementing policies and procedures that impact sustainability; it must include an appropriate balance of input and output measures and it must have a strong stakeholder component.

Hatzopoulou and Miller (2006) review indicators of sustainable transport for integrated policy appraisal in Canada. They note that there has been a growing interest in the issue by various Canadian institutions including: the Winnipeg's Centre for Sustainable Transportation (CST), the Victoria Transport Policy Institute (VTPI), Environment Canada (EC), and the National Round Table on the Environment and the Economy (NRTEE). The authors observe that while work on the topic is underway, further efforts are still needed in specific areas including but not limited to human exposure to air pollution and relations between levels of accessibility across socio-economic status. They also observe that the set of indicators proposed by the VTPI are considered to be more comprehensive than the indicators proposed by CST, since they are concerned with the three pillars of sustainability. By comparison, the indicators developed both by EC and NRTEE emphasize environmental quality at the expense of economic and social factors.

\section{I.2 Modeling Sustainability with ITLUMs}

As we noted earlier, ITLUMs have been used in the past to address the issue of urban sustainability in the European context. A number of European scholars carried out projects for this purpose, such as SPARTACUS system (European Commission, 1998) and more recently PROPOLIS (Lautso et al., 2002; Spiekermann and Wegener, 2004) and PROSPECTS (May et al., 2003; Minken et al., 2003). Efforts in these projects are centered on deriving indicators from existing integrated urban land use and transportation models, namely the MEPLAN, TRANUS and IRPUD models (see Wegener, 2004 for a detailed discussion of those models), to promote sustainable futures in a number of European cities.

The systems were developed to take into consideration five general goals that have been adopted in the European context to achieve a more sustainable urban future: (I) minimizing the consumption of space and natural resources, (2) rationalizing and efficiently managing urban flows, (3) protecting the health of urban populations, (4) ensuring equal access to resources and services, and (5) maintaining cultural and social diversity. In accordance with those goals, indicators have been identified within SPARTACUS, PROPOLIS and 
EUE • A tool for evaluating urban sustainability $\bullet$ a-32

Table I

Sustainable Indicator of the PROPOLIS System

\begin{tabular}{lll}
\hline & Theme & Indictor \\
\hline & Climate change & Greenhouse gases from transport \\
\cline { 2 - 3 } $\begin{array}{l}\text { Environmental } \\
\text { Indicators }\end{array}$ & $\begin{array}{l}\text { Acidifying gases from transport } \\
\text { Volatile organic compounds from transport }\end{array}$ \\
\cline { 2 - 3 } & $\begin{array}{l}\text { Consumption } \\
\text { of natural }\end{array}$ & $\begin{array}{l}\text { Consumption of mineral oil products, transport } \\
\text { Land coverage }\end{array}$ \\
& $\begin{array}{l}\text { resources } \\
\text { Environmental } \\
\text { quality }\end{array}$ & $\begin{array}{l}\text { Feed for additional new construction } \\
\text { Quality of open space }\end{array}$ \\
\hline
\end{tabular}

Exposure to PM from transport in the living environment

Exposure to $\mathrm{NO}_{2}$ from transport in the living environment

Health Exposure to traffic noise

Traffic deaths

Traffic injuries

Justice of distribution of economic benefits

Justice of exposure to PM

Equity Justice of exposure to $\mathrm{NO}_{2}$

Justice of exposure to noise

Social Indicators

Segregation

Housing standard

Opportunities Vitality of city centre

Vitality of surrounding region

Productivity gain from land use

Total time spent in traffic

Accessibility Level of service of public transportation and slow modes

and traffic Accessibility to city centre

Accessibility to services

Accessibility to open space

Transport investment costs

Transport user benefits

Total net Transport operator benefits

Economic

benefits from

Government benefits from transport

Indicators

transport

Transport external accident costs

Transport external emissions costs

Transport external greenhouse gases costs

Transport external noise costs

Source: Spiekermann and Wegener (2004)

। 
relevance of the chosen indicators, their effectiveness in representing different domains of sustainability, their ability to be policy sensitive and their efficacy in generating credible future forecasts. The PROPOLIS system hypothesizes thirty-five indicators that are classified into nine themes to assess the three dimensions of sustainability, as shown in Table I. Litman (2008) argues for the adoption of a standard set of sustainable indicators to be used as a benchmark when addressing sustainable transportation planning in North America and other places around the world. The PROPOLIS indicators, to a large extent, coincide with those proposed by Litman (2008). For the environmental pillar, PROPOLIS considers four themes that include global climate change, air pollution, consumption of natural resources and environmental quality. As for the social pillar, another four broadly defined themes are listed including health, equity, opportunities, accessibility and traffic. Finally, for the economic pillar, one theme is identified to reflect the total net economic benefit from transport. It is worth noting that not all of the indicators were usually calculated due to lack of data on particular indicators for some European cities (European Commissio PROPOLIS and SPARTACUS rely on a standard multi-criteria evaluation method to calculate the contribution of each indicator $x$ to the three pillars of sustainability. The idea is to translate the raw values of all indicators produced by the ITLUM into standardized indices (European Commission, 1998). For this, a linear value function is employed to determine the degree of influence of the indicator value. Accordingly, the raw value $v_{x}$ of any given indicator $\mathrm{x}$ is normalized to a new value $v_{x}^{*}$ on a scale of 0 to $\mathrm{I}$ using the linear function $v_{x}^{*}=a+b v_{x}$, where $a$ and $b$ are estimated parameters. SPARTACUS employs two arbitrary values vxmin and vxmax, which, respectively, describe the best $\left(v_{x}^{*}=0\right)$ and worst $\left(v_{x}^{*}=1\right)$ values of indicator $\mathrm{x}$ to determine the functional form of $v_{x}^{*}$ (that is, the parameters a and $\mathrm{b}$ ) (European Commission, 1998). However, setting vxmin and vxmax arbitrarily can result in errors suggesting that this indicator is influential or not. We account for this drawback by providing a systematic approach to determine vxmin and vxmax as will be discussed in the next section.

Multi-criteria evaluation is applied using the normalized indices $v_{x}^{*}$ to calculate an overall index SIP per pillar $p$ using exogenous weights ( $w I, w 2, \ldots, w k$ ) that reflect the importance of the $\mathrm{k}$ indicators of pillar p. Following Nijkamp et al. (1990), the general formula for calculating a sustainability index is given as follows:

$$
S I_{p}=\sum_{x=1}^{k} w_{x} \cdot v_{x}^{*}
$$

where $\mathrm{k}$ is the number of indicators that belongs

$$
\sum_{x=1}^{k} w_{x}=1
$$

to pillar $\mathrm{p}$, and $x=1$. The weights in PROPOLIS and SPARTACUS are the outcome of an internal expert survey performed to determine a common set of weights for the targeted study areas. The aggregation of indicators in equation $(I)$ is performed separately for the environmental, social and economic pillars of sustainability. An overall index can then be generated by taking a weighted average of the three indices pertaining to the three pillars of sustainability.

\section{A SIMULATION TOOL FOR URBAN SUSTAINABILITY}

In what follows, we report on the work that has been conducted to devise SUSTAIN, a simulation tool that can be used as an add-on module in an ITLUM to assess sustainable urban futures via simulations. The tool is integrated with IMULATE, a Canadian ITLUM developed for Hamilton, Ontario and Halifax, Nova Scotia. We first provide an overview of the IMULATE system. This is followed by a description of the modeling approach to devise SUSTAIN.

\section{I The IMULATE System}

IMULATE was first calibrated for the Census Metropolitan Area (CMA) of Hamilton, Ontario (an urban area of approximately 500,000 inhabitants according to the 200I Canadian Census) and became operational in the mid 1990s (Anderson et al., 1994). Since then, it has been used in a number of studies for the Hamilton region and has played a significant role in informing debates related to transportation infrastructure or/and land development projects (see for example Scott et al., 1997; Kanaroglou and South, 1999; Kanaroglou, 1999; Kanaroglou et al., 2000; Kang et al., 2008; Behan et al., 2008; Kanaroglou and Buliung, 2008). Recently, the model has been calibrated for Halifax, Nova Scotia, a CMA of approximately 360,000 inhabitants as documented by the 200I Canadian Census. The following discussion 


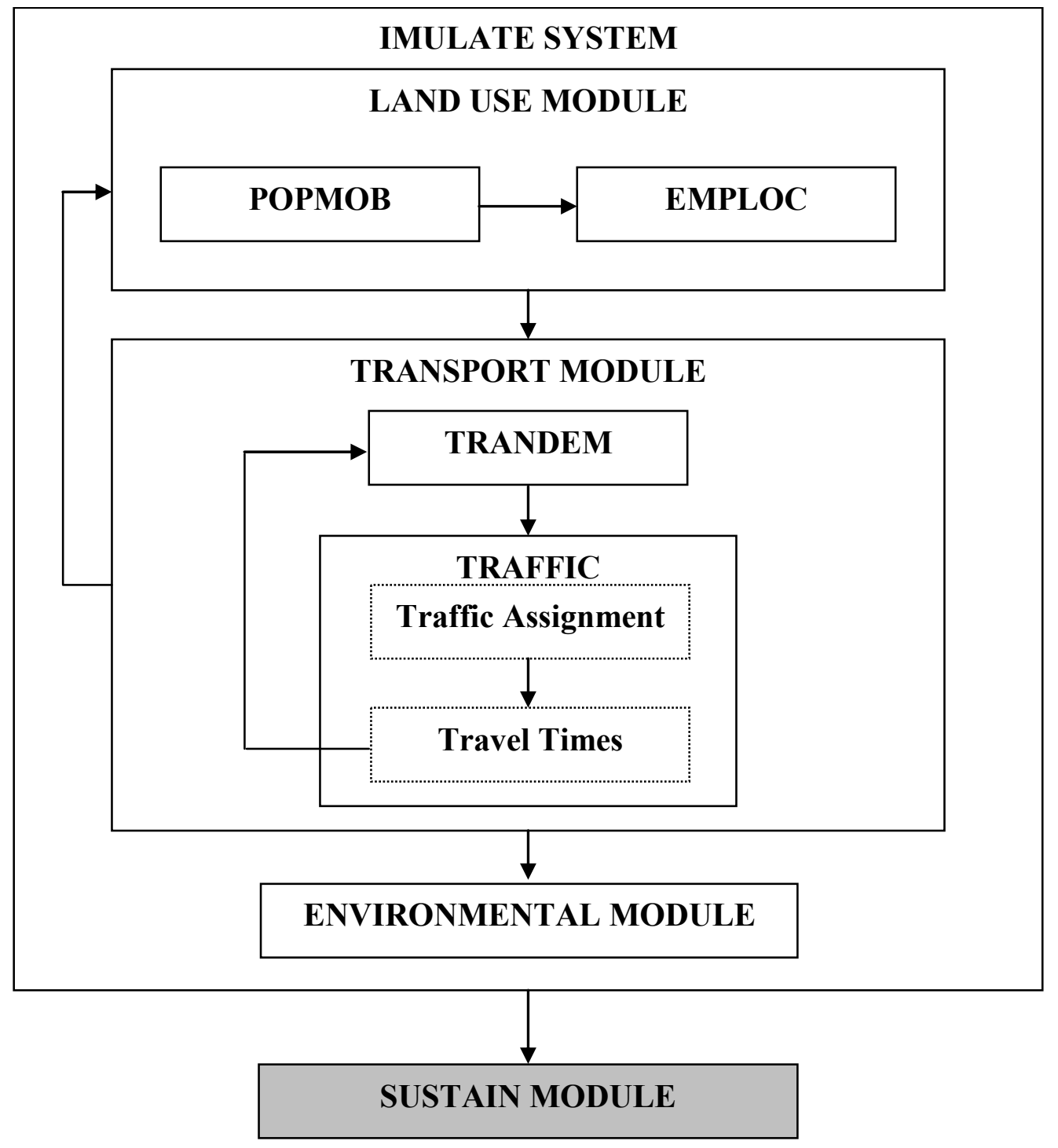

Fig. I - General Structure of IMULATE+

will focus on the IMULATE system of Hamilton, which consists of five main components (POPMOB, EMPLOC, TRANDEM, TRAFFIC and EMISSIONS), as shown in Figure I. The integration of the sustainability module (SUSTAIN) with IMULATE will result in IMULATE+, an ITLUM capable of simulating and evaluating the sustainability of Canadian Cities.

In essence, the model simulates changes in land use and travel demand over five-year intervals, the first of which corresponds to the period 1986 to 199I for Hamilton and 200I to 2006 for Halifax. More comprehensive discussions are available in Anderson et al. (1994), Buliung et al. (2005) and Kang et al. (2007). The Land Use Module of IMULATE consists of two submodules: POPMOB and EMPLOC. The first of these is a residential location model that relates to the intra-urban household mobility and the operation of the housing market over space and time. Household mobility between any two census tracts $k$ and $i$ is simulated with a multinomial logit model that predicts the probability, Pki, of moving from $k$ to $i$ in any given five-year interval. The utility of Pki is formulated as a function of location factors that pertain to the destination tract i. Those factors include newly constructed dwellings in i, proximity to hazards from i, housing cost in i, level of accessibility in i (determined by the Transport Module) and the physical distance between $k$ and i. EMPLOC, on the other hand, is a firm location model that relates to the intra-urban firm 
mobility and the associated location choice behaviour of firms in the CMA. The latter is simulated with a multinomial logit model that predicts the probability, $\mathrm{Pi}$, of choosing census tract $\mathrm{i}$ by a moving or newly formed firm. The utility of $\mathrm{Pi}$ is formulated as a function of location factors that pertain to the destination tract $i$. Those factors include proximity to the $C B D$, proximity to highways and main roads, proximity to regional malls, population size in $i$, household density in $i$, measures of agglomeration economies in $\mathrm{i}$ and the type of land use in i. While POPMOB predicts the change in the spatial distribution of households and population across the CMA, EMPLOC predicts the location of firms and employment across the CMA. Together, the two models determine a matrix that links place of residence to place of work (PORPOW) for all workers in the region (Kanaroglou, 1999).

TRANDEM, a submodule of the Transport Module, utilizes the PORPOW matrix to first predict the number of work, school and discretionary trips occurring between each pair of traffic analysis zones, which, in the case of IMULATE, correspond to Hamilton's I5I census tracts. Then, based on relative travel time and cost, trips are broken down via logit models into three modes: private automobile, public transit and walking (Kanaroglou, 1999). The TRAFFIC submodule translates the inter-zonal automobile trips generated by TRANDEM into flows on the road network by means of a stochastic user equilibrium traffic assignment model. At the same time, the effect of congestion on travel speed is estimated along individual links. Once network equilibrium is reached, the level of zonal accessibility (also known as the inclusive value) is calculated to be passed to the Land Use Module as a determinant of population and employment mobility for the subsequent simulation period. In this way, changes in the level of congestion on specific links due to new highway projects will have a direct bearing on residential and employment location choices and thereby commuting patterns. Consequently, IMULATE is capable of capturing the bidirectional relationship between land use and transportation.

After equilibrium is achieved and the traffic flows are determined, the Environmental Module is engaged. An EMISSIONS submodule is used to estimate emissions of carbon monoxide (CO), hydrocarbons (HC), nitrogen oxides (NOx) and particulate matters (PM2.5 and PMI0) for each link of the network via an interface between IMULATE and a well-established automobile emission model, MOBILE6.2C, the Canadian version of the MOBILE6.2 model.
MOBILE6.2 was developed by the U.S Environmental Protection Agency (EPA) and has been used in the United States in various air pollution applications. This model can estimate, for each category of vehicle, emissions generated over each trip of a given length. Such estimation depends upon the average speed over the trip as well as other factors that might affect emissions, such as air temperature and vehicle-fleet characteristics. The Environmental Module also provides estimates of aggregate fuel consumption in litres by passenger vehicles (Anderson et al., 1994).

\subsection{The SUSTAIN module}

We adopt the general objectives set by the SPARTACUS and PROPOLIS models to devise the SUSTAIN module for the Hamilton region. A number of sustainability indicators, as shown in Table 2, are selected to represent various aspects and domains of sustainability. The indicators are devised such that they are policy responsive and can be forecasted by IMULATE. For environmental indicators, we focus on measures that contribute to air pollution and consumption of non-renewable natural resources. Air pollution indicators are based on the output produced by Mobile6.2C. Those include emissions of greenhouse gases (CO), acidifying gases (NOx), volatile organic compounds $(\mathrm{HC})$, and particulate matters (PM2.5 and PMI0). It is well documented that increases in their levels can severely damage the environment and the transportation sector is a major source of these emissions. The indicator for any given pollutant is measured as the level of emission per 1000 inhabitants. Consumption of non-renewable natural resources refers to the consumption of fossil fuel manufactured from mineral oil products. The parameters of the fuel consumption model in IMULATE are the same as those employed in a study of transportation emissions and energy by the City of Toronto Planning and Development Department (Anderson et al., 1994). As in the case of emissions, total fuel consumption is measured per 1000 inhabitants. The indicator for the consumption of agricultural land (NR2) is calculated by measuring the amount of farmland and green space converted for human use. Accordingly, the indicator calculates the total area of farmland or green space converted for new land development in all census tracts of the city. 
EUE • A tool for evaluating urban sustainability • a-36

Table 2

Sustainable Indicators of the SUSTAIN module of IMULATE+

\begin{tabular}{|c|c|c|c|c|}
\hline Pillar & Theme & Label & Indicator & Definition \\
\hline & & $A P I$ & Greenhouse gases & Level of CO [kg] per 1000 inhabitants \\
\hline & & AP2 & Acidifying gases & Level of NOx [kg] per 1000 inhabitants \\
\hline \multirow[t]{10}{*}{ Environment } & Air pollution & AP3 & Volatile organic compounds & Level of $\mathrm{HC}[\mathrm{kg}]$ per 1000 inhabitants \\
\hline & & AP4 & Fine particles $<2.5 \mu \mathrm{m}$ & Level of PM2.5 [kg] per 1000 inhabitants \\
\hline & & AP5 & Fine particles $<10 \mu \mathrm{m}$ & Level of PMIO $[\mathrm{kg}]$ per 1000 inhabitants \\
\hline & Natural Resources & $N R I$ & Energy use from fossil fuels & Litters of Gas consumed per 1000 inhabitants \\
\hline & & NR2 & Consumption of green space & Arable land area [sq. km] converted to urbanized land \\
\hline & & $H L I$ & $\begin{array}{llll}\begin{array}{l}\text { Exposure } \\
\text { transport }\end{array} & \text { to } & & \text { from } \\
\end{array}$ & \\
\hline & & & & Number of people exposed to harmful levels of NOx per 1000 inhabitants \\
\hline & & HL2 & $\begin{array}{l}\text { Exposure to } \mathrm{CO} \text { from } \\
\text { transport }\end{array}$ & 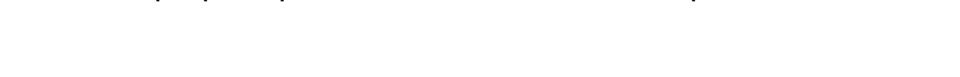 \\
\hline & Health & & & Number of people exposed to harmful levels of CO per 1000 inhabitants \\
\hline & & $H L 3$ & Traffic injuries & Number of traffic injuries per 1000 inhabitants \\
\hline \multirow[t]{8}{*}{ Society } & & HL4 & Traffic deaths & Number of deaths per 1000 inhabitants \\
\hline & Opportunity & $O P I$ & Vitality of CBD & Level of mix in land use in the CBD \\
\hline & & OP2 & Residential amenities & Level of mix in land use in the different neighbourhoods of the city \\
\hline & Accessibility & $A M I$ & Accessibility to CBD & Average travel times from all possible locations in the city to City centre \\
\hline & & AM2 & Accessibility to services & Average potential accessibility to services \\
\hline & Commute & AM3 & Vehicle kilometres traveled & Total VKT per 1000 inhabitants \\
\hline & & AM4 & Vehicle minutes traveled & Total VMT per 1000 inhabitants \\
\hline & Mobility & AM6 & Congestion index & Average level of congestion in city \\
\hline \multirow[t]{3}{*}{ Economy } & Cost (dollars) & $\mathrm{ECl}$ & Transport investment costs & Total dollars spend on maintaining road infrastructure \\
\hline & & EC2 & Transport commuting costs & Overall cost of commuting \\
\hline & & EC3 & Transport external costs & Total dollars due to externalities associated with health \\
\hline
\end{tabular}


For social indicators, measures have been generated for health, opportunity, and accessibility and mobility. It should be noted that equity indicators that measure justice with regards to exposure for different socio-economic population groups that can be classified according to income classes, as in PROPOLIS, are not included in the current version of SUSTAIN. The distribution of different socioeconomic groups over space cannot be predicted using IMULATE. This limitation will be addressed in future research. As for health indicators, there is a growing body of literature that is concerned with establishing a relation between air pollution exposure and health in the urban context (Jerrett et al., 2005). For our purposes, health indicators are used to assess the exposure to NOx and $\mathrm{CO}$ emissions, which emanate from passenger vehicles. Upcoming research will include a focus on generating exposure measures for particulate matter as well as exposure to noise sources. The latter will depend on data that is currently lacking for our study area.

The devised exposure indicators measure the shares of population living in areas where the concentration of pollutants exceeds safe guidelines. In order to calculate an exposure indicator, IMULATE+ calculates two surfaces to reflect the spatial distribution of population and the levels of concentration of the pollutant in question. The two surfaces are represented in raster Geographic Information System (GIS) format where the study area is divided into a finite number of grid cells $(500 \times 500$ meters). Population and pollution concentration are calculated for each grid cell $g$ during a given simulation. The exposure index is then calculated as follows:

$$
\text { Exposure }=\sum_{g} \operatorname{Pop}_{g} \delta_{g}
$$

$$
\delta_{g}= \begin{cases}1, & \text { Con }_{g}>\tau \\ 0, & \text { Con }_{g} \leq \tau\end{cases}
$$

where Popg is the size of population in grid cell $g$, Cong is the level of concentration of the pollutant in question in grid cell $g$, and $\tau$ is a threshold value for which the exposure to the pollutant becomes harmful.

The population surface is calculated from the zonal information produced by POPMOB. Population of a given zone (Popz) is distributed to the grid cells ( $g$
$=\mathrm{I}, 2, \ldots, \mathrm{Zg}$ ) that comprise zone $\mathrm{z}$ according to the following relation:

$$
\operatorname{Pop}_{g}=\operatorname{Pop}_{z} \frac{R L U_{g}}{\sum_{g=1}^{Z_{g}} R L U_{g}}
$$

where RLUg is the area of residential land use in grid cell g. On the other hand, the pollution concentration surfaces for NOx and $\mathrm{CO}$ are calculated using regression models that were estimated to relate the level of pollution concentration in grid cell $g$ to the amount of generated traffic on the road links that are in the vicinity of the grid cell. The regression models substitute the integration and utilization of the TAPM dispersion model (Hurley et al., 2005) with IMULATE. This approach is followed since the combination of TAPM with IMULATE to generate pollution concentration surfaces, while simulating a scenario will require days of computer processing, given the current computational power (i.e. Intel Core 2 Duo $2.0 \mathrm{GHz}$ CPU). The dependent variable in the regression model is based on concentration measures that were initially obtained from running TAPM with road link emissions for the year 2006. Two concentration surfaces per pollutant were generated with TAPM to account for the two prevailing south west and north east wind directions in the Hamilton region.

Table 3 presents the results of the estimated regression models. In each model, three independent variables were used: (I) Tflow300g: the total traffic from passenger cars on all road links that are within a buffer of 300 meters from the center of grid cell g, (2) NRDUMg: a dummy variable set to I if grid cell $g$ does not intersect with a major road or highway, 0 otherwise, and (3) DWSPg: a dummy variable set to I if grid cell $g$ is down wind from a source of road pollution, 0 otherwise. The estimation results in Table 3 indicate well-behaved models with high R-squares and significant parameters that meet our a priori expectations. The concentration of pollution in the grid cell will tend to increase as the generated traffic from passenger cars will increase, as discerned from the Tflow300g variable. The models indicate that locations that are down wind from a source of road pollution will have higher concentrations of pollution, other things being equal, as determined by the DWSPg variable. Finally, locations that are not proximal to roads and highways will have lower pollution concentrations as can be seen in results obtained for the NRDUMg variable. During a simulation, 
EUE • A tool for evaluating urban sustainability $\bullet$ a-38

Table 3

Estimated parameters of the regression models for pollution concentration surfaces

\begin{tabular}{lllll}
\hline & NOx (SW) & NOx (NE) & CO (SW) & CO (NE) \\
\hline Constant & 27.1880 & 32.1823 & 105.0497 & 279.0702 \\
& $(148.9553)$ & $(159.6775)$ & $(21.7447)$ & $(40.6378)$ \\
Tflow300 $_{g}$ & 0.0011 & 0.0016 & 0.0313 & 0.0480 \\
& $(69.2458)$ & $(92.3383)$ & $(73.5875)$ & $(82.0019)$ \\
NRDUM $_{g}$ & -1.8750 & -1.7301 & -29.1355 & -34.0333 \\
& $(-8.5923)$ & $(-7.2410)$ & $(-5.0158)$ & $(-4.2237)$ \\
DWSP $_{g}$ & 25.4468 & 30.1839 & 848.9048 & 845.9685 \\
& $(94.1950)$ & $(110.4497)$ & $(108.1018)$ & $(98.5191)$ \\
\hline Multiple R & 0.8735 & 0.9071 & 0.8953 & 0.8859 \\
R $^{2}$ & 0.7630 & 0.8228 & 0.8016 & 0.7849 \\
Adjusted R & 0.7628 & 0.8228 & 0.8015 & 0.7847 \\
Standard Error & 7.3143 & 8.0097 & 194.6146 & 270.1187 \\
Observations & 5504 & 5504 & 5504 & 5504 \\
F-statistic & 5901.2363 & 8515.5471 & 7409.2382 & 6687.9022 \\
Significance F & 0.0000 & 0.0000 & 0.0000 & 0.0000 \\
\hline Note:t-sts for the & & &
\end{tabular}

Note: $t$-stats for the estimated parameters are the values in parenthesis.

IMULATE+ will utilize the estimated parameters in Table 3 along with the generated link traffic flows from the TRAFFIC submodule to calculate the concentrations Cong(SW) and Cong(NE) that correspond to the south west and north east wind directions, respectively. For a given pollutant, the value of Cong required in equation 3 is then calculated as follows: ... (5)

$$
\operatorname{Con}_{g}=\frac{2}{3} \operatorname{Con}_{g}(S W)+\frac{1}{3} \operatorname{Con}_{g}(N E)
$$

The above formulation is based on empirical evidence that indicates a respective two thirds south west (SW) and one third north east (NE) wind prevalence during a given year in the Hamilton region.

To develop health indicators, we calculate the number of traffic related injuries and deaths per 1000 inhabitants. For this, we use recent rates on injuries (I $=669$ injuries per billion VKT) and deaths $(\mathrm{d}=9.3$ deaths per billion VKT) from Transportation Canada to establish a relation between traffic accidents (i.e. number of injuries/deaths) and the generated traffic (Vehicles Kilometres Traveled [VKT]) for a given scenario. The reason for adopting a simple approach to measure injuries and deaths is the lack of spatial data on traffic accidents for our study area. Should spatial data on traffic accidents become available a more elaborate approach will be devised to determine the number of injuries and deaths.

The second theme of indicators within the social pillar relates to social opportunities that are represented by the vitality of the Central Business District (CBD) and the level of residential amenities in the urban area. The vitality indicator (OPI) is based on measuring the level of mixed land use densities (i.e. co-existence of population and employment) in the central part of the city. Similarly, better residential amenities can be achieved with a high level of mixed land use densities in the different neighbourhoods (census tracts) of the city. Following the literature, an entropy index (Elr) that takes on a value between 0 and $I$ can be used to quantify the level of mix of land use densities in region $r$ : 


$$
E I_{r}=1-\left(-\frac{\sum_{a} P d_{a}^{r} \ln P d_{a}^{r}}{\ln L}\right)
$$

where $P d_{a}^{r}$ is the proportion of land use density of type a relative to the total density obtained from all available land uses $(a=I, 2, \ldots, L)$ in region $r$. In our case, densities pertaining to population $(a=I)$ and employment $(a=2)$ are used to evaluate the level of mix in land use in region $r$, where $L=2$. Population density is based on the output produced by POPMOB whereas employment density is based on the output produced by EMPLOC. OPI is calculated with equation 6 by setting $r$ as the CBD, where the CBD corresponds to the set of census tracts that form the old part of the city. OP2, on the other hand, is calculated by averaging the entropy indices (Elr) for all census tracts $(r=I, 2, \ldots,|5|)$ comprising the Hamilton area. According to equation 6, mixed land use that reflects a higher level of vitality or residential amenities is achieved when the values for OPI and OP2 are close to 0 .

The third theme of indicators within the social pillar relates to accessibility, levels of commuting and mobility in the city. The CBD plays an important role from a cultural, economic and social perspective. Therefore, changes in accessibility to the CBD due to imposed land use and transportation policies can have a social impact on the citizens of the city. We define accessibility to CBD as the average travel time it takes to move from all locations in the city to the CBD in a congested situation. Accessibility to the CBD will become poor as the average congested travel times from all locations to the CBD increase. Within a service based economy, access to services is an important aspect of everyday life. We measure accessibility to services by averaging the potential accessibility to service employment for all origin census tracts $i$ in the city. Potential accessibility to services from origin census tract $i$ is calculated as follows:

$$
A_{i}=\sum_{j=1}^{n} S E_{j} / C_{i j}^{2}
$$

where SEj is service employment of census tract $j$ and $\mathrm{C}_{\mathrm{ij}}$ is the travel time from origin tract $\mathrm{i}$ to destination tract $j$. The latter is endogenously determined by the traffic assignment routine of the transportation module.

Indicators pertaining to the level of commuting include VKT per 1000 inhabitants and VMT per 1000 inhabitants. The general idea here is that higher values of VKT and VMT will be associated with higher levels of commuting distance and time, and this can have negative impacts on society due to wasteful commuting (Ma and Banister, 2006). The final social indicator is based on measuring the overall level of congestion to depict the ease of mobility in the city. The indicator suggests that a higher congestion index will be associated with a lower level of mobility. VKT and VMT are calculated from the road link flows produced by the TRAFFIC module:

$$
V K T=\sum_{l} \text { flow }_{l} \cdot \text { length }
$$

$$
V M T=\sum_{l} \text { flow }_{l} \cdot \text { ttimes }_{l}
$$

where flowl is the total flow of passenger vehicles on road link I, lengthl is the length [km] of link I, and ttimesl is the congested travel times [minutes] required to traverse link $\mathrm{I}$. The congestion index is based on an average of the congestion indices of all individual links comprising the transportation network:

$$
A M 6=\frac{\sum_{l} \text { flow }_{l} / \text { capacity }_{l}}{N}
$$

where capacityl is the design capacity of link I and $\mathrm{N}$ is the total number of links of the transportation network.

The economic sustainability indicators are devised to capture three monetary costs (in Canadian dollars) that are endured as a result of travel. The first indicator is the cost that road suppliers endure in order to maintain or build new road infrastructure. Intuitively, more usage of the transportation network, reflected by an increase in VKT, will increase the cost of maintaining existing infrastructure or building new supplies. Using figures from Transportation Canada, we estimate the total cost associated with maintaining/building a kilometre of infrastructure to be $\$ 0.027$ per VKT. We use this estimate along with the 
predicted VKT from IMULATE+ to calculate ECI. The second economic indicator (EC2) corresponds to the users of the road infrastructure and measures the cost associated with commuting. The total commuting cost in minutes can be calculated as follows:

$$
C C=\frac{\sum_{i} \sum_{j} C_{i j} \cdot T_{i j}}{\sum_{i} \sum_{j} T_{i j}}
$$

where $\mathrm{Cij}$ is the inter-zonal travel time to commute from origin zone $i$ to destination zone $j$, and $\mathrm{Tij}$ is the total number of trips from origin $i$ to destination j. As before, using figures from Transportation Canada, we estimate the total cost in dollars per one minute of user commute to be $\$ 0.114$. This figure is used in conjunction with equation II (i.e. $0.114 \times \mathrm{CC}$ ) to estimate EC2. Finally, the last economic indicator (EC3) is devised to account for the external costs (i.e. health and fatalities) that are associated with transportation. Health costs include, but are not limited to, exposure to various pollutants as well as traffic injuries. Traffic fatalities are among the most devastating external economic costs societies will ever experience. To capture those effects, we employ the health indicators ( $\mathrm{HLI}, \ldots$, HL4) to calculate indicator EC3 as follows:

$$
E C 3=C H \times(H L 1+H L 2)+C I \times H L 3+C D \times H L 4
$$

where $\mathrm{CH}$ is the hospital admission cost (\$) per case due to illness associated with exposure to harmful pollutants, $\mathrm{Cl}$ is the hospital admission cost (\$) per case due to illness associated with a traffic injury and $C D$ is the cost $(\$)$ associated with a traffic fatality. Using figures from the Ontario Medical Association, $\mathrm{CH}$ is estimated at an average rate of $\$ 6,158$ per exposure case. On the other hand, using numbers from Transportation Canada, $\mathrm{Cl}$ and CD are estimated to be $\$ 28,000$ and $\$ 1,560,000$ per case of traffic injury and traffic fatality, respectively.

\subsection{Sustainable Indices Evaluation}

For any indicator $x$ that pertains to one of the three pillars of sustainability, SUSTAIN will generate three values $\left(v_{x}, v_{x}^{\min }\right.$ and $\left.v_{x}^{\max }\right)$ that represent the raw, hypothetical minimum and hypothetical maximum values of the indicator, respectively, where $v_{x}^{\min } \leq v_{x} \leq v_{x}^{\max }$. Similar to SPARTACUS and PROPOLIS, the generated value $v_{x}$ is normalized to a new value $v_{x}^{*}$ on a scale of 0 to $\mathrm{I}$, to be able to compare indicators directly. The normalization is achieved by using the following formula:

$$
v_{x}^{*}=\frac{\left(v_{x}-v_{x}^{\min }\right)}{\left(v_{x}^{\max }-v_{x}^{\min }\right)}
$$

To assess the sustainability of the simulated scenario, each indicator is assigned an exogenous weight in the range of 0 to 100 percent to directly reflect its importance. For instance, an indicator with a weight of $80 \%$ is deemed more important than an indicator with a weight of $20 \%$. Accordingly, an exogenous list of weights $W=\left\{w_{1}, w_{2}, \ldots, w_{k}\right\}$ corresponding to the $\mathrm{k}$ indicators of a given pillar $\mathrm{p}$ is provided as input to calculate the index $S I_{p}$, as in equation I. An overall index $\mathrm{SI}$ is then calculated by average the SIp values of the three pillars, where $p=$ \{I: Environment, 2: Society and 3: Economy\}.

SUSTAIN employs a systematic method that relies on the well-known Transportation Problem (TP) to determine the values of $v_{x}^{\min }$ and $v_{x}^{\max }$. Traditionally, the transportation problem has been used in excess commuting studies to calculate the optimal (minimum) distribution of trips for all origin-destination pairs in the city, such that the average journey-to-work trip length is minimized and the demand (represented by the distribution of jobs at the different destination zones) is met (White, 1988; Ma and Banister, 2006). The idea here is to move people closer to their places of work so that the overall commute is minimized. Recently, the concept of the theoretical maximum commute is incorporated along with the conventional minimum excess commute to examine the feasible commuting range for a particular urban form (Horner, 2002). The general premise of the maximum commute is to move people as far as possible from their places of work so that the overall commute is maximized. It should be noted that the minimum and maximum commutes represent hypothetical situations that may never occur in reality. Nonetheless, given the current urban form (i.e. distribution of houses and jobs) the actual commute will always fall within the minimum and maximum commuting range. It can be argued that the observed commuting pattern of a city (derived 
from the PORPOW matrix) is more efficient if it is close to the minimum commute. Following these ideas, SUSTAIN utilizes the simulated urban form from POPMOB and EMPLOC to formulate and optimize the following transportation problem:

Objective function:

$$
Z=\frac{1}{W} \sum_{i} \sum_{j} C_{i j} T_{i j}
$$

\section{Constraints:}

$$
\begin{array}{ll}
\sum_{i} T_{i j}=\operatorname{Emp}_{j} & \forall j=1,2, \ldots, 151 \\
\sum_{j} T_{i j}=\operatorname{Pop}_{i} & \\
\forall i=1,2, \ldots, 151 & \forall i, j
\end{array}
$$

where $W$ is the total number of commuters, Empj is the total number of jobs in destination zone $\mathrm{j}$, Popi is the total number of commuting workers living in origin zone $\mathrm{i}$, and $\mathrm{Cij}$ and $\mathrm{Tij}$ are previously defined. The minimum and maximum trip matrices are calculated by, respectively, minimizing and maximizing the objective function $Z$ in equation 14 subject to the three listed constraints. The minimal solution of the above linear program will result in Tij's that correspond to the minimal commute in the study area. Those Tij's are then assigned to the transportation network using the TRAFFIC submodule. The resulting link flows are used to calculate link emissions and energy consumption levels via the Environmental module. The outputs are then employed to calculate $v_{x}^{\min }$ for all the indicators listed in Table 2. In a similar fashion, the maximum Tij's from maximizing $Z$ is fed into the TRAFFIC and Environmental modules and the outputs are employed to calculate the $v_{x}^{\max }$ values.

\section{MODEL IMPLEMENTATION}

The modeling framework of SUSTAIN is developed as a Visual $\mathrm{C}++$ simulation program and integrated with the IMULATE system to form IMULATE+. The new simulation tool is endowed with a friendly Graphical User Interface (GUI) to enable users to provide inputs and retrieve outputs in an efficient and fast manner. For inputs, the interface enables the user to alter the weights for the different indicators of the system. SUSTAIN utilizes various data files that are generated during simulations to calculate $v_{x}, v_{x}^{\min }$ and $v_{x}^{\max }$. The results are displayed in a spreadsheet, which can be exported to text files for reporting. Given the provided weights, SUSTAIN also calculates the normalized value of each indicator following equation 13 and the results are summarized and displayed in both tabular and graphical format.

Similar to the work of Pfaffenbichler and Shepherd (2002), Vold (2005) and more recently Jonsson (2008), in our following analysis, we will test SUSTAIN by simulating four scenarios that present four different patterns of residential land development in the Hamilton CMA for the time period 200I - 2006. The objective is to identify which of these patterns are the most and least sustainable. We assume a total of 20,000 new residential dwellings to be constructed in the Hamilton CMA in this time period. Such information forms the supply of the land market for the POPMOB model, which predicts the spatial distribution of population in the tracts of the CMA. The four scenarios are as follows:

1- Base Case: This is a business as usual scenario where the distribution of the 20,000 new dwellings across the tracts of the CMA follows the observed past trends published by Statistics Canada for 1991-1996 and 1996-200I.

2- Urban Residential Intensification (URI): Urban residential intensification is a commonly advocated land use policy under the umbrella of new urbanism and smart growth strategies (Behan et al., 2007). To reflect urban residential intensification, we evenly assign the 20,000 new dwellings across the central tracts shown in Figure 2 .

3- Urban Expansion: In this scenario, we assume that the city will continue its horizontal land expansion where new development will mainly occur in the densely populated built-up area in the inner suburbs of the city. Accordingly, the new dwellings are evenly assigned to the inner suburban tracts shown in Figure 2.

4- Urban Sprawl: Land development in this scenario is assumed to follow a sprawled pattern where new development is mainly occurring in the outer suburbs of the city. To 
EUE • A tool for evaluating urban sustainability • a-42

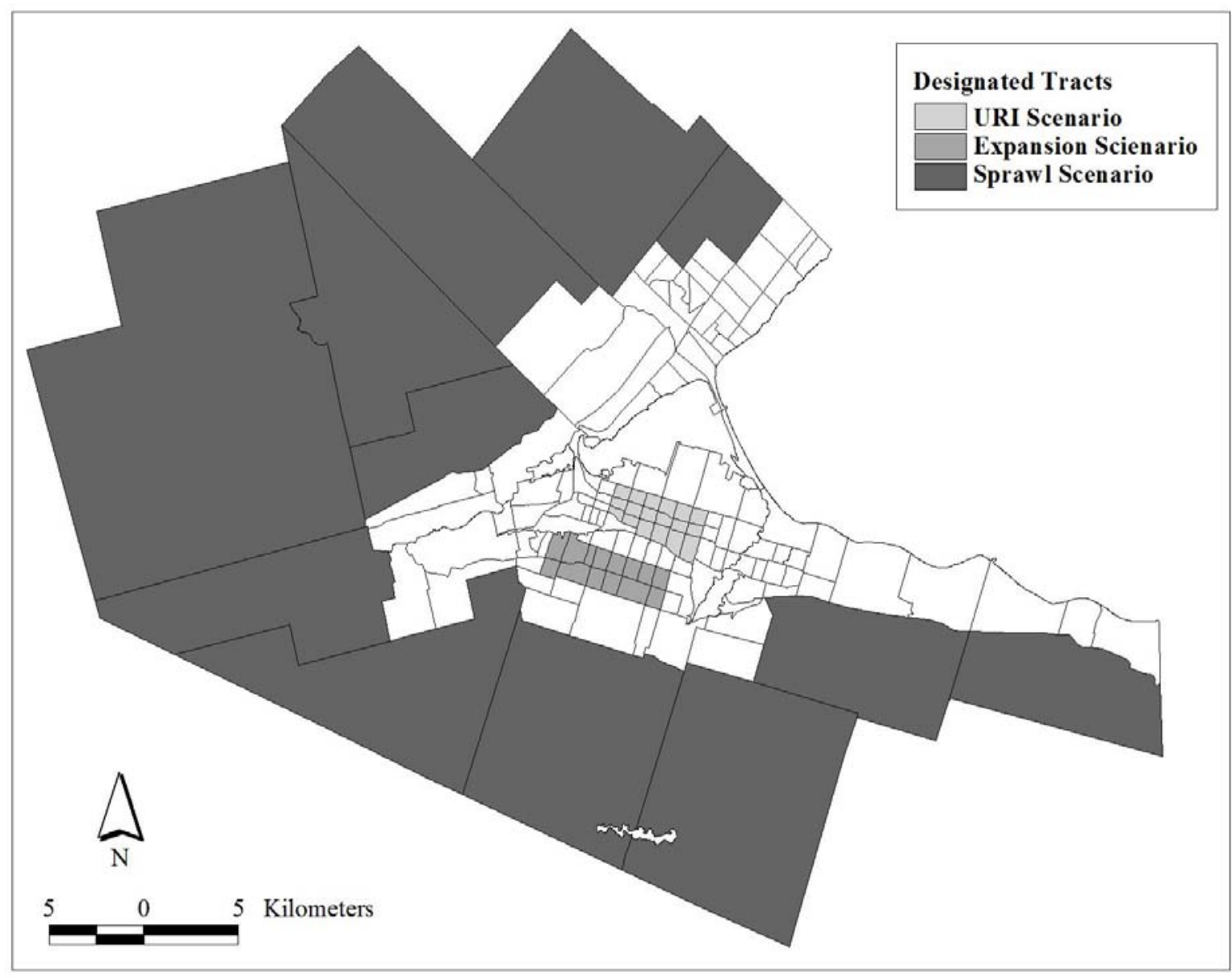

Fig. 2 - Designated census tracts for residential land development in the Hamilton CMA

capture this effect, we evenly distribute the new dwelling far away from the core in tracts that are at the fringe of the city, as shown in Figure 2.

Since the above scenarios are for illustrative purposes only, we assign equal weights among the indicators of any given pillar for simplification. However, it should be noted that when performing appraisal analysis of potential future scenarios, the assigned weights of the indicators will play a major role in determining the value of the sustainability indices in equation I. Typically, the value of these weights is determined by collecting information through stated preference surveys such as the one conducted by Hunt (200I) for the City of Edmonton, Alberta, Canada. The objective of such surveys is to evaluate the attitudes of citizens towards a range of themes that relate to urban sustainability. This can help identify which sustainability indicators are more important, and therefore assign them with higher weights when evaluating the examined future scenarios. Future research will focus on determining plausible values for the weights of the devised sustainability indicators for Hamilton following the approach provided in Hunt (200I). 
EUE • A tool for evaluating urban sustainability $\bullet a-43$

Table 4

Estimated sustainable indices for simulated scenarios, $200 \mathrm{I}$ - 2006

\begin{tabular}{|c|c|c|c|c|c|}
\hline \multirow[b]{2}{*}{ Indicator } & & \multicolumn{4}{|c|}{ Scenarios } \\
\hline & & Base & URI & Expansion & Sprawl \\
\hline \multicolumn{6}{|l|}{ Environmental } \\
\hline Greenhouse gases & $A P I$ & 0.0655 & 0.0680 & 0.0668 & 0.0750 \\
\hline Acidifying gases & $A P 2$ & 0.0824 & 0.0849 & 0.0824 & 0.0905 \\
\hline Volatile organic compounds & AP3 & 0.0531 & 0.0547 & 0.0534 & 0.0614 \\
\hline Fine particles $<2.5 \mu \mathrm{m}$ & AP4 & 0.0916 & 0.0949 & 0.0915 & 0.0989 \\
\hline Fine particles $<10 \mu \mathrm{m}$ & AP5 & 0.0916 & 0.0949 & 0.0915 & 0.0989 \\
\hline Energy use from fossil fuels & $N R I$ & 0.0892 & 0.0926 & 0.0892 & 0.0973 \\
\hline Consumption of green space & NR2 & 0.0641 & 0.0000 & 0.0000 & 0.1311 \\
\hline Overall Indicator $\left(S I_{l}\right)$ & & 0.5375 & 0.4899 & 0.4748 & 0.6530 \\
\hline \multicolumn{6}{|l|}{ Social } \\
\hline Exposure to $\mathrm{NO}_{x}$ from transport & HLI & 0.0091 & $0.007 \mid$ & 0.0098 & 0.0126 \\
\hline Exposure to $\mathrm{CO}$ from transport* & HL2 & 0.0000 & 0.0000 & 0.0000 & 0.0000 \\
\hline Traffic injuries & HL3 & 0.0532 & 0.0551 & 0.0531 & 0.0574 \\
\hline Traffic deaths & $H L 4$ & 0.0533 & 0.0551 & 0.0533 & 0.0574 \\
\hline Viability of the CBD & $O P I$ & 0.0029 & 0.0082 & 0.0017 & 0.0021 \\
\hline Residential amenities & OP2 & 0.0009 & 0.0009 & 0.0009 & 0.0009 \\
\hline Accessibility to CBD & AMI & 0.0332 & 0.0369 & 0.0313 & 0.0427 \\
\hline Accessibility to services & AM2 & 0.0315 & 0.0370 & 0.0327 & 0.0434 \\
\hline Vehicle kilometres travelled & AM3 & 0.0538 & 0.0557 & 0.0538 & 0.0581 \\
\hline Vehicle minutes travelled & AM4 & 0.0252 & 0.0260 & 0.0248 & 0.0327 \\
\hline Congestion index & AM5 & 0.0566 & 0.0602 & 0.0561 & 0.0609 \\
\hline Overall Indicator $\left(\mathrm{SI}_{2}\right)$ & & 0.3197 & 0.3421 & 0.3176 & 0.3680 \\
\hline \multicolumn{6}{|l|}{ Economic } \\
\hline Transport investment costs & $E C l$ & 0.2114 & 0.2190 & 0.2113 & 0.2283 \\
\hline Transport commuting costs & $E C 2$ & 0.1695 & 0.1782 & 0.1691 & 0.1888 \\
\hline Transport external costs & EC3 & 0.2178 & 0.2257 & 0.2177 & 0.2352 \\
\hline Overall Indicator $\left(\mathrm{SI}_{3}\right)$ & & 0.5987 & 0.6229 & 0.5981 & 0.6522 \\
\hline Overall $(S I)$ & & 0.4853 & 0.4850 & 0.4635 & 0.5578 \\
\hline
\end{tabular}

Note: * Exposure to $\mathrm{CO}$ is 0 due to low levels of $\mathrm{CO}$ concentration from traffic.

The results of the simulations are summarized in Table 4. It is worth noting that the system is developed such that better environmental, social or economic conditions are achieved when the normalized value $v_{x}^{*}$ of any particular indicator $\mathrm{x}$ is closer to 0 . The same applies to the Slp indicators. As such, a value close to I postulates an undesirable condition. The sprawl scenario appears to provide the most undesirable outcome with an overall sustainability index of 0.56 . By comparison, the expansion scenario appears to provide the most desirable overall index (0.46), which appears to be very close to the indices achieved from the base and URI scenarios. The same observations apply when examining the calculated indices per pillar of sustainability. While the results from the sprawled scenario are not very surprising, those pertaining to the URI scenario are more interesting. The implementation of an URI scenario will result in better environmental conditions compared to the base case and sprawled scenario. However, it fails to create better social conditions when compared to the base and expansion scenarios. The sources of this undesirable condition are congestion and low mixing of land uses, as discerned from the relatively higher values of the congestion and viability of CBD indices ( 0.06 and 0.008). Nonetheless, the URI scenario appears to mitigate exposure to pollution as can be inferred from the exposure to NOx. It is worth noting that the above 
results are partially driven by the assigned weights. Different results regarding the sustainability of the simulated scenarios would have emerged if we assigned higher weights to particular indicators. Therefore, attention should be given to the assigned values of the weights.

\section{CONCLUSIONS AND DIRECTIONS FOR FUTURE RESEARCH}

This paper presented a framework for assessing sustainability of cities using large-scale integrated transport and land use models (ITLUMs). The efforts presented here add to the scarce literature on the development of simulation tools to assess urban sustainability. This research also paves the road for future work to assess the sustainability of urban development practices in Canadian cities by providing an operational tool for this purpose. A review of the literature suggests that the application of large-scale simulation models to assess urban sustainability is still at its infancy, although the art of developing integrated urban models goes back to the early 1960s. To date, there are at least 20 operational integrated urban models that have been developed for various cities around the world (Wegener, 2004). However, the use of such models to study the different aspects of urban sustainability is still limited (Buliung et al., 2006).

As noted earlier, a process of identification of sustainable indicators within ITLUMs should be carried out such that the indicators are chosen for their relevance, representation, policy sensitivity, and prediction ability (Kelly, 1998; Hardi and Pinter, 1995). Accordingly, a number of indicators could be calculated, but some might require advanced modeling techniques or detailed data. Nonetheless, we have demonstrated that the issue of urban sustainability can still be assessed using existing models as in the case of SPARTACUS, PROPOLIS and PROSPECTS. Our framework can be implemented in various Canadian cities making use of an operational travel demand model or ITLUM. However, improving the predictive ability of existing ITLUMs can assist in improving the quality of the devised indicators. It is well documented that microsimulation ITLUMs can help on this front (Miller et al., 2004). Unfortunately, very few operational models of this sort exist at the present time. Until such models are operational, there is the need to extend existing zone-based models as shown in this paper to make informed decisions regarding transportation planning and infrastructure projects.

Although this tool accounts for various domains and aspects of sustainability, there is still room for future research to enhance the performance of such tools and allow them to explicitly account for other important aspects of urban sustainability. The limitations suffered in this research were mainly due to a lack of appropriate data. Therefore, upcoming research will focus on addressing these limitations to improve the performance of the SUSTAIN module. In addition, it will enable SUSTAIN to generate indices for exposure to particulate matter and exposure to noise pollution. It will also enhance the predictive ability of POPMOB in order to predict the breakdown of population by different socioeconomic groups according to age (as in Kanaroglou et al., 2007). In this way, SUSTAIN will be able to generate social equity indicators such as justice with regards to exposure for particular age groups that are more susceptible to pollution. Furthermore, future improvements along the lines of developing microsimulation models, as noted above, will enhance the core of the ITLUM being used. The objective will be to enable the model to generate more detailed land use and transportation related outputs that can help calculate vital sustainability indicators. Examples of the latter would include: daily average per capita time spent in active transportation, per capita transportation cost by mode of travel, impervious developed floorspace for urban use. Finally, since SUSTAIN is mainly developed to help inform and advocate the sustainability of different land use and transportation policies in Canadian cities, our research efforts in the near future will be focused on utilizing the system for this purpose.

\section{ACKNOWLEDGEMENT}

This research has been made possible through a financial contribution from Infrastructure Canada. The second author is grateful to the Canada Research Chair program for financial support. The views expressed herein do not necessarily represent the views of the Government of Canada.

\section{BIBLIOGRAPHIE}

Anderson, W., P. Kanaroglou, and E. Miller (1994). Integrated Land Use and Transportation Model for Energy and Environmental Analysis: A report on Design and Implementation, Unpublished Report, McMaster University, Hamilton, ON, Canada.

BASLER, E. (1998). "Measuring the Sustainability of Transport", Materials of NRP 4I, Vol. M3, National Research Programme 4I, p. I-I3.

Behan, K., H. MaOh, and P. Kanaroglou (2008). "Simulating and evaluating smart growth strategies: evidence from the CMA of Hamilton, Ontario", The Canadian Geographer, vol. 52, no. 3, p. 29I-308.

BLACK, W. (2002). "Sustainable Transport and Potential Mobility”, EJTIR, vol. 2, no. 3/4, p. I79-196. 
Black, J., A. Paez, and P. Suthanaya (2002). "Sustainable Urban Transportation: Performance Indicators and Some Analytical Approaches", ASCE Journal of Urban Planning and Development, vol. 128, no. 4, p. 184-209

BRUECKNEW, J. (2000). "Urban sprawl: diagnosis and remedies", International Regional Science Review, vol. 23, no. 2, p.|60-I7I.

Buliung R., P. Kanaroglou and H. MaOH (2005). "GIS, objects and integrated urban models", in LEEGOSSELIN, M. and S. DOHERTY (Ed.), Integrated Land use and Transportation Models: Behavioral Foundations, Oxford, UK, Elsevier Science Ltd, p. 207-230.

Buliung, R., M. Hatzopoulou, and M. RoOrda (2006). "Plugging the "Environment" into Integrated Urban Models: Recent Progress and Research Directions", in Proceedings of the 4 /st Annual Meeting of the Canadian Transportation Research Forum, May 28-3I, Quebec City, Quebec, Canada, p. 668 - 68I

Carruthers, J. and G. Ulfarsson (2002). "Fragmentation and sprawl: evidence from interregional analysis", Growth and Change, vol. 33, p. 312-340.

Deakin, M., P. Huovila, S. RaO, M. SunikKa, and R. VReeker (2005). "The assessment of sustainable urban development”, Building Research \& Information, vol. 30, no. 2, p. 95-108.

Dieleman, F., M. DijSt and G. BurghouWt (2002). "Urban form and travel behavior: micro-level household attributes and residential context", Urban Studies, vol. 39 , no. 3, p. 507-527.

EUROPEAN COMMISSION (1998). SPARTACUS: System for Planning and Research in Towns and Cities for Urban Sustainability - Final Report EC Environment and Climate Research Program, DGXII, Helsinki 2nd Edition).

HANDY, S. (2005). "Smart growth and the transportationland use connection: what does the research tell us?", International Regional Science Review, vol. 28, no. 2, p. |46-167.

Hardi, P. and L. Pinter, (1995). Models and Methods of Measuring Sustainable Development Performance Report, Ontario: Institute for sustainable Development.

Hatzopoulou, M. and E. Miller (2006). "Indicators of Sustainable Transport for Integrated Policy Appraisal: Linking Sustainable Transport Plans with DecisionMaking in the Greater Toronto Area (GTA)", in Proceedings of New Scholars Conference on Sustainable Transportation, May 15-16, 2006, Bloomington, Indian, USA.

HORNER, M. (2002). "Extensions to the concept of excess commuting", Environment and Planning A, vol. 34, p. 543566.

HUNT, J. (200I). "Stated preference analysis of sensitivities to elements of transportation and urban form", Transportation Research Record: Journal of Transportation Research Board, vol. 1780. p. 76-86.
Hurley P., W. Physick, A. LUhar, and M. EdWARds (2005). "The Air Pollution Model (TAPM) Version 3. Part 2: Summary of some verification studies", CSIRO Atmospheric Research Technical Paper, no. p. 72. 36.

JeON, C, A. AmeKudZI, and R. Guensler (2008). "Sustainability Assessment at the Transportation Planning Level: Performance Measures and Indexes", in Proceedings of the 87th Annual Meeting of the Transportation Research Board (TRB), Washington, DC, January 10-14, 2008, USA, p. I-26.

JeON, C. and A. AmekudzI (2005). "Addressing Sustainability in Transportation Systems: Definitions, Indicators, and Metrics", Journal Of Infrastructure Systems, vol. II, no. I, p. $3|-5|$.

Jerrett, M., A. Arain, P. Kanaroglou, B. Beckerman, D. potoglou, T. Sahsuvaroglu, J. Morrison, and C. GIOVIS (2005). "A review and evaluation of intra-urban air pollution exposure models", Journal of Exposure Analysis and Environmental Epidemiology, vol. I5, p. 185204.

JONSSON, R. (2008). "Analysing sustainability in a land-use and transport system", Journal of Transport Geography, vol. 16, p. 28-41.

Kanaroglou, P. (1999). "New transportation links and urban air quality: the Red Hill Creek expressway, Hamilton, ON". Paper presented at The 6th International Conference on Environmental Science and Technology, Pythagorion, Samos, Greece.

Kanaroglou, P. and R. South (1999). "Energy and urban form: special feature: can urban form affect transportation energy use and emissions?", Energy studies review, vol. 9, no. 2, p. 22-40.

Kanaroglou, P., R. Buliung, and B. Taylor (2000). "Mobile Source Emissions in Urban Areas: The Relative Contribution of Trucks", in Proceedings of Fifth International Conference on the protection and restoration of the Environment, vol. 2, p. 991-998.

Kanaroglou, P. and Buliung, R. (2008). "Estimating the contribution of commercial vehicle movement to mobile emissions in urban areas", Transportation Research Part E:Logistics and Transportation Review, vol. 44, no. 2, p. $260-276$.

Kanaroglou, P. and D. ScOtT (2002). "Integrated urban transportation and land-use models for policy analysis, in Dijst, M. (Ed.), Governing Cities on the Move: Functional and Management Perspectives on Transformations of Urban Infrastructure in European Agglomerations, Aldershot (UK), Ashgate, p. 43-75.

Kanaroglou, P., H. Maoh, K. Newbold, D. Scott, and A. PÁEZ (2007). "A demographic model for small area population projections: An application to the Census Metropolitan Area (CMA) of Hamilton in Ontario, Canada", Centre for Spatial Analysis Working Paper Series, no. 023, Centre for Spatial Analysis, McMaster University, Hamilton, ON, Canada, p. I - 24. 
Kang, H., D. Scott, P. Kanaroglou, and H. MaOH (2007). "An investigation of highway improvement impacts in the Hamilton CMA, Canada", Environment and Planning B (in press).

Lautso, K., K. SpiekermanN, and M. Wegener (2002). "Modelling Policies for Urban Sustainability". Paper presented at the 42 ${ }^{\text {nd }}$ Congress of the European Regional Science Association (ERSA), Dortmund, 27-3I August 2002.

KELLY, K. (1998). "A system approach to identifying decisive information for sustainable development", European Journal of Operational Research, vol. 109, p. 452-464.

LITMAN, T. (2008). "Sustainable Transportation Indicators", Victoria Transport Policy Institute, Online report, January 2008, http://www.vtpi.org/sustain/sti.pdf (last accessed January 20-2008).

MA, K. and D. BANISTER (2006). "Excess commuting: a critical review”, Transport Reviews, vol. 26, no. 6, p. $749-767$.

may, A., A. Karlstrom, N. Marler, B. Minken, A. Monzon, M. Page, P. Pfaffendickler, and S. Shepherd (2003). "A decision makers guidebook. Deliverable 15 of the PROSPECTS project", in Institute for Transportation Studies, University of Leeds, Leeds

Miller, E., J. Hunt, J. Abraham, and P. Salvini (2004). "Microsimulating urban systems", Computers, environment and urban systems, vol. 28, p. 9-44.

Minken, H., R. Jonsson, S. Shepherd, T. Jarvi, A. May, M. Page, A. Pearman, P. Pfaffenbichler, P. Timms, and A. VOLD (2003). "A methodological guidebook. Deliverable 14 of the PROSPECTS project", Institute of Transport Economics, Oslo, Norway.

Morse, S., N. Mcnamara, M. ACHOlo, and B. OKWOl (200I) "Sustainability indicators: the problem of integration", Sustainable Development, vol. 9, p. I-I5.

NeWMAN, P. and J. KeNWORTHY (1999). Sustainability and cities: overcoming automobile dependence, Washington, DC, Island Press, 450 pages.

Nijkamp, P., P. RietVeld, and H. Voogd (1990). Multicriteria evaluation in physical planning, Amsterdam, NorthHolland, 232 pages.

Pfaffenbichler, P. and S. ShepHerd (2002). "A dynamic model to appraise strategic land-use and transport policies", in European Journal of Transport and Infrastructure Research, vol. 2, p. 255-283.

SCOTt, D., P. Kanaroglou and W. ANderson (1997). "Impacts of commuting efficiency on congestion and emissions: Case of the Hamilton CMA, Canada", in Transportation Research D: Transport and Environment, vol. 2, p. 245-257.

SpiekermanN, K. and M. Wegener (2004). "Evaluating Urban Sustainability Using Land Use Transport Interaction Models", EJTIR, vol. 4, no. 3, p. 25I-272.
VOLD, A. (2005). "Optimal land use and transport planning for the greater Oslo area", Transportation Research Part A: Policy and Practice, vol. 39, p. 548-565.

Wegener, M. (2004). "Overview of Land Use Transport Models", in Hensher,D., Button,K., Haynes, K., and Stopher, P. (Ed.), Handbook of Transport Geography and Spatial Systems, Amsterdam; London, Elsevier Ltd, p. |27-I46.

WHITE, M. (1988). "Urban commuting journeys are not wasteful", The Journal of Political Economy, vol. 96, p. 1097-III0. 